\title{
Utilização de revestimento soldado para o aumento da vida útil de ponteiras sulcadoras em semeadoras adubadoras
}

\author{
FERREIRA, M.F'; REIS, Â.V. DOS ${ }^{2}$; MACHADO, A.L.T. ${ }^{3}$ \\ ${ }^{1}$ Prof. Adjunto. Departamento de Engenharia Rural, Faculdade de Agronomia Eliseu Maciel, Universidade Federal de Pelotas. \\ Pelotas/RS \\ ${ }^{2}$ Prof. Associado. DER/FAEM/UFPel. \\ ${ }^{3}$ Prof. Associado. DER/FAEM/UFPel.
}

Palavras-chave: desgaste abrasivo, perda de massa, revestimento duro, semeadura

\begin{abstract}
Resumo
Este trabalho teve o objetivo de verificar uma alternativa técnica e econômica para aumentar a vida útil das ponteiras de hastes sulcadoras de semeadoras adubadoras, através da adição de soldagem de revestimento em pontos estratégicos da ferramenta. Para isto aplicou-se eletrodos revestidos e arame tubular, nas direções longitudinal e transversal da superfície da ponteira. As avaliações comparativas foram executadas em um solo de textura francoarenosa sem mobilização prévia. 0 delineamento experimental foi inteiramente casualizado e para cada nível de desgaste foi feita a comparação das médias por análise de variância. 0 desgaste das ponteiras foi avaliado pela pesagem destas em intervalos de distância percorrida de $10,5 \mathrm{~km}$ até o limite de $52,5 \mathrm{~km}$, quando a ponteira testemunha obteve o desgaste de $38,4 \%$ da massa inicial. Todas as soldagens aumentaram a vida útil da ponteira, sendo que o tratamento com arame tubular apresentou o melhor desempenho com menor custo.
\end{abstract}

\section{Addition of hardfacing to increase the lifespan of hoe openers in no-till planters}

Key words: Abrasive wear, weight loss, hardfacing, seeding

\begin{abstract}
This work aimed to examine a technical and economically alternative for the increase of the lifespan of hoe openers in no-till planters, through the application of hard facing by flux cored arc welding in strategic points of the tool. The hard material was applied using four covered electrodes and cored wire over the surface of the openers in the longitudinal and transverse directions. Tests were performed on sandy loam soil without previous tillage. The experimental design was randomized and the mean values of treatments compared by analysis of variance for each level of wear. The wear of the hoes was assessed by weighing them in intervals of $10.5 \mathrm{~km}$ to the limit of $52.5 \mathrm{~km}$, when the control hoe wear achieved $38.4 \%$ of the initial mass. All weldings have increased the lifespan of the tip, whereas treatment with cored wire showed the best performance with lowest cost.
\end{abstract}




\section{INTRODUÇÃO}

O desgaste de componentes mecânicos em equipamentos industriais e agrícolas representa um dos principais fatores de depreciação de capital e de fontes de despesas com manutenção, influindo nos custos diretos de produção (reposição ou recuperação de peças) e também nos custos indiretos como superdimensionamento de componentes, deterioração de equipamentos e interrupçóes no trabalho (LEITE; MARQUES, 2009). Sob esse aspecto, o estudo do desgaste dos materiais utilizados em implementos agrícolas é fundamental para a previsão da durabilidade de um equipamento (MOURAD; SANTOS, 2003).

$\mathrm{O}$ fenômeno do desgaste tem onerado as indústrias no mundo todo,provocando falhas prematuras em peças e equipamentos. Segundo Moraes (2005) o desgaste abrasivo é um dos principais envolvidos na reduçáo da vida útil e encontrado com maior frequência, o que lhe garante importância econômica. Estatísticas indicam que de 1,0 a 5,0\% do produto interno bruto (PIB) do Brasil são gastos pela ação direta ou indireta do desgaste.

$\mathrm{Na}$ bibliografia existem diversas definiçôes de desgaste. Para Brandi (2004) este é o dano a uma superfície sólida envolvendo perda progressiva de material devido à movimentação relativa entre a superfície de um ou vários materiais. Segundo Moraes (2005) é a perda progressiva de material da superfície de um corpo como consequência do movimento relativo de um segundo corpo sobre o primeiro. Segundo Bhole\&Yu (1992), o desgaste pode ser considerado como a remoção de material de superfícies sólidas devido ao resultado da ação mecânica. Entre os desgastes (usualmente expresso em perda de massa), o abrasivo é o que melhor descreve a ação do solo sobre as ferramentas em contato com o mesmo.

O desgaste pode ser mantido dentro de determinados limites aceitáveis desde que se tenha o conhecimento dos esforços e mecanismos a que a peça encontra-se submetida, a fim de que sua capacidade de trabalho não seja prejudicada.

Dados técnico-científicos indicam muitas maneiras de se reduzir o desgaste por abrasão em elementos de máquinas. Nalbant\&Palali (2011) empregaram três revestimentos (nitreto de titânio - TiN, níquel depositado por redução química e cromo duro aplicado por eletrólise) em relhas de arado de aivecas fabricadas com aço DIN EN 10083, as quais foram submetidas, juntamente com as relhas não revestidas, ao trabalho em canal de solo até o desgaste dos revestimentos. Segundo os autores, embora o revestimento de TiN tenha apresentado mais resistência ao desgaste, existe ainda uma necessidade de novos progressos e melhorias para proporcionar mais soluçôes econômicas para o futuro próximo. Outra abordagem foi empregada por Machado et al. (2008), que empregaram ponteiras sulcadoras utilizadas em semeadoras-adubadoras construídas de ferro fundido nodular austemperado, ADI (AustemperedDuctile Iron), com o fim de minimizar o desgaste abrasivo provocado pelo solo, obtendo um aumento médio de $21 \%$ na vida útil destas em relação às originais, fabricadas de aço SAE 1060 forjado.

Como o desgaste é um fenômeno tipicamente superficial, a solda de revestimento também tem sido utilizada com sucesso na prevençáo e na manutenção das desgastadas (BRANDI, 2004). Esse recobrimento é a deposição de uma liga especial na superfície sujeita a esta deterioração. Isto pode ser obtido pela aplicação de cordóes de solda com características de resistência ao desgaste na superfície da parte em questão (LEITE; MARQUES, 2009). Para tanto, utilizam-se diferentes processos, técnicas e consumíveis para o recobrimento do componente ou reposição do metal desgastado em serviço.

Revestimento superficial utilizando cromo duro em ferramentas sujeitas ao desgaste abrasivo por partículas de solo na indústria sucroalcooleira foi estudado por Lima \&Ferraresi (2009), material este que proporciona elevada resistência ao desgaste, em virtude de sua dureza superficial e de sua microestrutura cristalina.

Tradicionalmente a aplicação do revestimento duro tem sido realizada com eletrodos revestidos, entretanto a alternativa usando arames tubulares tem se tornado viável devido à alta produtividade e à qualidade da solda (LIMA; FERRARESI, 2009).

Como o desgaste é um fenômeno superficial, onde as partículas do solo, em especial as que caracterizam a fração areia do solo, a qual tem elevada dureza, remove material das ponteiras sulcadoras, a adição de um 
material mais duro que o aço original (cromo duro), depositado por meio de soldagem sobre os locais de maior exposição ao desgaste, pode reduzir o desgaste da ferramenta, aumentado a sua vida útil.

Este trabalho teve o objetivo de analisar uma alternativa técnica e econômica para o aumento da vida útil das ponteiras de hastes sulcadoras de semeadoras adubadoras de semeadura direta, através da adição de soldagem de revestimento em pontos estratégicos da ferramenta.

\section{MATERIAL E MÉTODOS}

Os testes de determinação do desgaste das ponteiras das hastes sulcadoras foram realizados em quatro áreas experimentais no município de Pelotas, RS, Brasil, nas coordenadas de $031^{\circ} 42.4964^{\prime}$ latitude sul e $052^{\circ} 18.6779^{\prime}$ longitude oeste. Em função dos espaçamentos entre linhas das hastes da semeadora, da velocidade de deslocamento e das distâncias percorridas, foram utilizados aproximadamente 21 ha. Nesta regiáo, o tipo de solo é classificado como planossolo. Em toda a área o solo não recebeu preparo primário ou secundário, simulando desta maneira o sistema plantio direto.

A caracterização do solo do ponto de vista físico (densidade, teor de água e textura do solo), até a profundidade de $90 \mathrm{~mm}$, foi feita conforme procedimentos padronizados dos laboratórios de análises.

O solo das áreas estudadas apresentou $197,5 \mathrm{~g} \mathrm{~kg}^{-1}$ de argila, 227,2 $\mathrm{g} \mathrm{kg}^{-1}$ de silte e 550,3 $\mathrm{g} \mathrm{kg}^{-1}$ de areia em média. Utilizando o triangulo textural (STRECK, et al., 2002), pode-se classificá-lo como franco-arenoso. A densidade do solo, em todas as áreas, foi alta, sendo seu valor médio de $1.723 \mathrm{~kg} \mathrm{~m}^{-3}$. Este fato pode ser explicado pela criação de bovinos de forma extensiva com lotação duas vezes maior do que a recomendada.

A resistência mecânica do solo à penetração foi mensurada de forma sequencial a cada $10 \mathrm{~mm}$ de profundidade no intervalo de 0 a $90 \mathrm{~mm}$ no perfil utilizando penetrógrafo digital de campo modelo PLG1020 da marca Falker ${ }^{\oplus}$, equipado com sistema eletrônico de aquisição de dados e ponteira tipo 2. A partir dos valores obtidos de resistência mecânica à penetração, determinou-se o índice de cone, ou seja, a resistência média nesse intervalo de profundidade obtendo se na média $1.900 \mathrm{kPa}$. Os teores de água no solo entre as áreas foram semelhantes, com média de $14,4 \mathrm{~g} \mathrm{~kg}^{-1}$ no período de realização do trabalho.

Para a imposição do desgaste das ponteiras foi utilizada uma semeadora-adubadora de fabricação da Indústria de Máquinas e Implementos Agrícolas KF Ltda, modelo KF 5030-A geração 4.100, com seis linhas espaçadas de $400 \mathrm{~mm}$, com mecanismo sulcador de fertilizantes do tipo haste com ponteira, ajustada para uma profundidade de trabalho de 90 $\mathrm{mm}$. A fonte de potência empregada foi um trator marca Valmet, modelo $880 \mathrm{com}$ duas rodas motoras (4x2) e potência no motor de 59,6 kW. A velocidade de deslocamento do conjunto trator e semeadoraadubadora foi de $6,0 \mathrm{~km} \mathrm{~h}^{-1}$, alcançada utilizandose a $4^{a}$ marcha reduzida com rotação no motor de $2.000 \mathrm{rpm}$.

Para o experimento foram utilizados cinco revestimentos duros sobre as ponteiras novas originais e uma testemunha totalizando seis tratamentos, os quais foram avaliados em cinco distâncias percorridas $(10,5 ; 21,0 ; 31,5 ; 42,0$ e $52,5 \mathrm{~km})$, com três repetiçôes. As variáveis de resposta foram as perdas de massa (percentagem em relação à massa inicial) determinadas em cada uma das distâncias percorridas. O delineamento experimental foi inteiramente casualizado e para cada nível de desgaste (distância percorrida) foi feita a análise de variância.

Através da análise dos desgastes determinados por Machado et al. (2008) se observaram os locais de maior perda de massa na superfície da ponteira. A partir destas informaçôes determinou-se a direção dos passes de soldagem dos eletrodos de revestimento duro sobre a sua superfície. As ponteiras foram revestidas com adição de material soldado no Laboratório de Pesquisa e Desenvolvimento da empresa ESAB em Belo Horizonte, MG. Os eletrodos foram especificados pelo fabricante em função da utilização e finalidade da proteçáo ao desgaste da ferramenta.

Cada conjunto de três peças soldadas, com os mesmos consumíveis e de acordo com as duas direçóes de passes de cordóes, foi identificado com número 1 , 2, 3, 4 e 5. Nos conjuntos 1 e 2 foi utilizada uma "almofada", que consiste na deposição de uma camada 
de solda, na regiáo de alto risco de desgaste, com um material de alta ductilidade antes da adição do material de revestimento propriamente dito, com o objetivo de se evitar a fissuração no material base (MODENESI et al., 2010), em função de seu elevado teor de carbono (aço SAE 1060, 0,55 a 0,65\% de C).

A seguir apresenta-se a descrição da soldagem de cada conjunto:

Conjunto 1 - Um passe de "almofada" com o eletrodo revestido "A" com diâmetro $2,50 \mathrm{~mm}$ de aço contendo $0,04 \%$ de C, $0,84 \%$ de $\mathrm{Si}, 0,78 \%$ de $\mathrm{Mn}$, 28,20 de Cr, 10,30\% de $\mathrm{Ni}$ e $0,01 \%$ de Mo, que é indicado para aços de baixa soldabilidade, e um passe com o eletrodo revestido " $\mathrm{B}$ " com diâmetro 3,25 mm, de aço contendo 3,68\% de C, 1,75\% de Si, 0,18\% de $\mathrm{Mn}, 30,00 \%$ de Cr e dureza de 60 HRC, indicado para o revestimento de partes sujeitas à abrasão severa, logo por cima do anterior, no sentido de soldagem longitudinal (Figura 1-A).

Conjunto 2 - Um passe de "almofada" com o eletrodo "A" e um passe com o eletrodo "B" logo por cima do anterior no sentido de soldagem transversal (Figura 1-B).

Conjunto 3 - Dois passes com o eletrodo revestido "B", um em cima do outro, no sentido de soldagem longitudinal. As peças foram pré-aquecidas a $250{ }^{\circ} \mathrm{C}$ (Figura 1-C).

Conjunto 4 - Um passe com o arame tubular com diâmetro 2,40 mm, de aço contendo 3,68\% de C, 1,95\% de Si, 1,30 de Mn, 23,50\% de Cr e dureza de $57 \mathrm{HRC}$, indicado para peças que necessitem elevada resistência à abrasão, no sentido de soldagem longitudinal. As peças foram pré-aquecidas a $250^{\circ} \mathrm{C}$ (Figura 1-D).

Conjunto 5 - Dois passes com o eletrodo revestido "B" um em cima do outro no sentido de soldagem transversal. As peças foram pré-aquecidas a $250^{\circ} \mathrm{C}$ (Figura 1-E).

Conjunto 6 (testemunha - sem solda) - Ponteira confeccionada em aço SAE 1060 forjado onde não foi realizado qualquer tratamento, tendo sua característica original especificada pelo fabricante tendo na sua composição principal $98,0 \%$ de $\mathrm{Fe}, 0,58 \%$ de C, $0,82 \%$ de $\mathrm{Mn}$ e $0,38 \%$ de Si entre outros elementos (Figura 1-F). Sua dureza superficial foi de 30,0 HRC obtida através do durômetro, marca Mitutoyo, modelo
963-101.

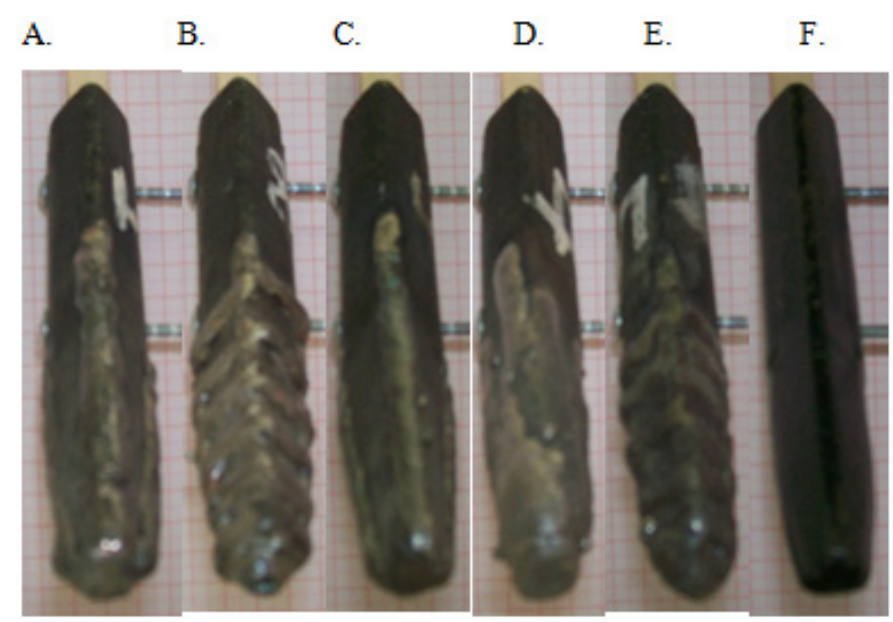

Figura 1. Vista frontal de todos os tratamentos mostrando a direção dos passes dos eletrodos de revestimento duro longitudinalmente ao eixo da ponteira e testemunha. (A) Cj 1 - conjunto 1, (B) Cj 2 - conjunto 2, (C) Cj 3 - conjunto 3, (D) Cj 4 - Conjunto 4, (E) Cj 5 Conjunto 5, (F) Cj sem solda.

Os testes foram realizados de forma que cada conjunto de seis ponteiras fosse utilizado simultaneamente durante 1,75 h (distâncias de 10,$5 ; 21,0 ; 31,5 ; 42,0$ e $52,5 \mathrm{~km}$ ), intercalando-se as repetiçóes, de modo a sofrerem a menor influência possível das variaçóes naturais dos atributos e parâmetros do solo (textura, densidade, resistência mecânica do solo à penetração, teor de água). As ponteiras sem revestimento e revestidas iniciaram o teste novas, ou seja, sem desgaste e após o período de $1,75 \mathrm{~h}$, em cada repetiçáo e a cada etapa de desgaste, foram retiradas das hastes da semeadora, limpas e pesadas em balança digital com resolução de 0,01 g.

$\mathrm{Na}$ análise econômica foram utilizadas as quantidades de eletrodos e arames tubulares dos revestimentos gastos para recobrir as ponteiras, assim como o tempo de soldagem (incluindo o serviço de mão de obra) para se calcular o custo total por ponteira $(\mathrm{R} \$)$. O custo por unidade linear trabalhada $(\mathrm{R} \$ \mathrm{~km}$ 1) foi obtido a partir do custo total por ponteira e as distâncias percorridas $(\mathrm{km})$ até que todas as ponteiras fossem utilizadas por $52,5 \mathrm{~km}$ (aproximadamente 10 horas de trabalho quando passa a existir a possibilidade de dano da ponteira e da haste sulcadora).

Para análise dos dados utilizou-se a análise de variância, com as estimativas do contraste entre médias realizadas pelo teste de Tukey em nível de 5\% de probabilidade através da planilha eletrônica Excel ${ }^{\circledR}$. 


\section{RESULTADOS E DISCUSSÃO}

A Figura 2 apresenta a perda de massa média das três repetiçóes em relação à massa original das ponteiras.

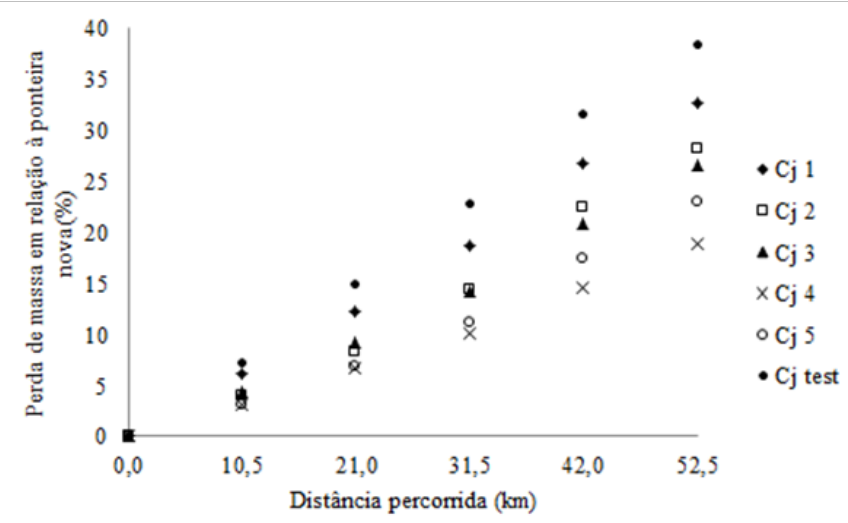

Figura 2. Evolução da perda de massa em relação à massa inicial dos conjuntos

A redução da massa da ponteira sem solda mostrou um desempenho semelhante ao encontrado por Machado et al. (2008), onde, em 9,0 h de trabalho $(45,0 \mathrm{~km})$, perdeu cerca de $40 \%$ da massa original. A ponteira utilizada por Machado etal. (2008), construída com ADI atingiu um desgaste de aproximadamente $21,0 \%$ da massa original no mesmo período de tempo (percurso). A ponteira com soldagem de revestimento com arame tubular (conjunto 4) revelou um desgaste de $18,8 \%$ inferior aquela e com um percurso superior $(52,5 \mathrm{~km})$. Esse desgaste é estatisticamente o mesmo obtido pelos conjuntos $2(28,3 \%), 3(26,6 \%)$ e 5 (23,0\%).

A análise estatística das perdas de massa em relação aos conjuntos sem desgaste encontra-se na Tabela 1 .

Tabela 1. Análise estatística das perdas de massa em relação à massa inicial dos conjuntos

\begin{tabular}{|l|l|l|l|l|l|}
\hline \multirow{2}{*}{ Conjunto } & \multicolumn{5}{|l|}{ Distância percorrida $(\mathrm{km})$} \\
\cline { 2 - 6 } & 10,5 & 21,0 & 31,5 & 42,0 & 52,5 \\
\cline { 2 - 6 } & \multicolumn{5}{|l|}{ Perda de massa (\%) } \\
\hline s/ solda & $7,2 \mathrm{a}$ & $14,8 \mathrm{a}$ & $22,7 \mathrm{a}$ & $31,6 \mathrm{a}$ & $38,4 \mathrm{a}$ \\
\hline 1 & $6,2 \mathrm{ab}$ & $12,3 \mathrm{ab}$ & $18,6 \mathrm{ab}$ & $26,8 \mathrm{ab}$ & $32,7 \mathrm{ab}$ \\
\hline 2 & $4,0 \mathrm{bc}$ & $8,3 \mathrm{bc}$ & $14,5 \mathrm{bc}$ & $22,4 \mathrm{bc}$ & $28,3 \mathrm{bc}$ \\
\hline 3 & $4,3 \mathrm{bc}$ & $9,2 \mathrm{bc}$ & $14,1 \mathrm{bc}$ & $20,9 \mathrm{bcd}$ & $26,6 \mathrm{bc}$ \\
\hline 4 & $3,1 \mathrm{c}$ & $6,6 \mathrm{c}$ & $10,2 \mathrm{c}$ & $14,6 \mathrm{~d}$ & $18,8 \mathrm{c}$ \\
\hline 5 & $3,1 \mathrm{c}$ & $6,9 \mathrm{c}$ & $11,2 \mathrm{c}$ & $17,5 \mathrm{~cd}$ & $23,0 \mathrm{bc}$ \\
\hline CV (\%) & 22,4 & 16,1 & 11,9 & 12,6 & 12,9 \\
\hline
\end{tabular}

Médias com mesmo índice na coluna não diferem significativamente pelo teste de Tuckey ao nível de 5\% de probabilidade.
Quando se comparam esses resultados com os obtidos por Yazici (2011), que verificou o desgaste apresentado por relhas de arado de aivecas revestidas com solda com eletrodo e arame tubular de aço cromo (ambos com 35,0\% de Cr), constata-se que o desgaste obtido foi entre 36,9 e $46,1 \%$ menor do que aquele apresentado pela relha sem solda (em $100 \mathrm{~km}$ de deslocamento), sendo, portanto, semelhante à redução obtida aqui (37,7\% na média dos conjuntos 2, 3, 4 e 5 em relaçáo à testemunha). Vale ressaltar que o teor de areia do solo empregado pelos autores variava de 410 a $460 \mathrm{~g} \mathrm{~kg}^{-1}$, igualmente alto como o solo do presente estudo. Verifica-se, entáo, que o emprego de revestimentos soldados a base de $\mathrm{Cr}$ podem ser uma solução efetiva para a redução do desgaste de ferramentas de trabalho do solo.

De acordo com o teste F, em todos os deslocamentos realizados, pode-se afirmar que o teste foi significativo ao nível de $5 \%$ de probabilidade e os tratamentos possuem efeitos diferentes sobre a perda de massa em relação à inicial. Observa-se que as soldagens de revestimento realizadas possuem efeitos diferentes sobre a perda de massa das ponteiras em todas as distâncias percorridas. $O$ conjunto 1 não diferiu do conjunto testemunha, enquanto o 4 apresentou diferença significativa em relação à testemunha e ao conjunto 1 , mas não diferiu dos demais com exceção do conjunto 2 para $42,0 \mathrm{~km}$. O conjunto sem solda e o conjunto 1 apresentam desgaste significativamente maiores em relação aos conjuntos 4 e 5 .

Os resultados também mostraram que a direção da aplicação dos cordóes de solda, longitudinais ou transversais em relação ao eixo da ponteira, não interferiu significativamente no desgaste, pois os tratamentos 3 e 5 , que foram soldados com o mesmo eletrodo, apresentaram desgastes estatisticamente iguais.

$\mathrm{Na}$ avaliação da viabilidade econômica dos processos de proteção da ponteira foi construída a Tabela 2. 
Tabela 2. Análise econômica dos revestimentos em relação à testemunha

\begin{tabular}{|l|l|l|l|l|l|l|}
\hline \multicolumn{2}{|l|}{$\begin{array}{l}\text { Custo total da } \\
\text { soldagem } \\
(\mathrm{R} \$)\end{array}$} & $\begin{array}{l}\text { Custo total por } \\
\text { ponteira } \\
(\mathrm{R} \$)\end{array}$ & $\begin{array}{l}\text { Desgaste em relação } \\
\text { ao original } \\
(\%)\end{array}$ & $\begin{array}{l}\text { Vida útil estimada } \\
\text { (km) }\end{array}$ & $\begin{array}{l}\text { Custo por unidade } \\
\text { linear } \\
(\mathrm{R} \$ \mathrm{~km}-1)\end{array}$ \\
\hline S/ solda & 0,00 & 25,00 & 38,4 & 52,5 & 0,47 \\
\hline Conjunto 1 & 10,01 & 35,01 & 38,4 & 60,8 & 0,58 \\
\hline Conjunto 2 & 15,89 & 40,89 & 38,4 & 72,5 & 0,56 \\
\hline Conjunto 3 & 9,38 & 34,38 & 38,4 & 76,9 & 0,45 \\
\hline Conjunto 4 & 3,41 & 28,41 & 38,4 & 108,4 & 0,26 \\
\hline Conjunto 5 & 14,95 & 39,95 & 38,4 & 89,9 & 0,44 \\
\hline
\end{tabular}

Os custos totais de soldagem variaram entre $\mathrm{R} \$ 3,41$ a $\mathrm{R} \$ 15,89$ e utilizando-se o valor da ponteira original testemunha de R \$25,00 obtiveram-se os custos totais por ponteira entre este valor e $\mathrm{R} \$ 40,89$. Para se comparar os revestimentos e a testemunha se calculou os custos por ponteira por unidade linear trabalhada, ficando entre os valores de $0,26 \mathrm{R} \$ \mathrm{~km}^{-1}$ a $0,58 \mathrm{R} \$$ $\mathrm{km}^{-1}$ o conjunto 4 e a testemunha respectivamente. Tomando-se como referência a testemunha se observa que o conjunto 1 e 2 obtiveram valores maiores, não sendo viável economicamente o seu uso. Foram viáveis economicamente os conjuntos 3,4 e 5 que tiveram valores inferiores a $0,47 \mathrm{R} \$ \mathrm{~km}^{-1}$ ficando o melhor desempenho entre os eletrodos revestidos o "B" no sentido de soldagem transversal com a economia de $0,03 \mathrm{R} \$ \mathrm{~km}^{-1}$ por ponteira. $\mathrm{O}$ arame tubular utilizado obteve o menor valor $\left(0,26 \mathrm{R} \$ \mathrm{~km}^{-1}\right)$ com economia de $0,21 \mathrm{R} \$ \mathrm{~km}^{-1}$ por ponteira.

\section{CONCLUSÕES}

1 - Aumenta-se a vida útil das ponteiras de sulcadores de semeadoras de plantio direto por meio da adição de material soldável em locais identificados como mais sujeitos a abrasão.

2 - Os melhores tratamentos foram o arame tubular seguido do eletrodo revestido "B" com sentido de soldagem transversal, obtendo perdas de massa de $18,8 \%$ e $23,0 \%$ com $52,5 \mathrm{~km}$ de deslocamento.

3 - Os tratamentos mais viáveis economicamente foram o arame tubular, o eletrodo revestido "B" sentido de soldagem transversal e o eletrodo revestido "B" sentido de soldagem longitudinal com 0,26, 0,44 e $0,45 \mathrm{R} \$ \mathrm{~km}^{-1}$ respectivamente.

\section{LITERATURA CITADA}

BHOLE, S. D.; YU, H. Abrasive wear evaluation of tillage materials.Lubricating Engineering, v.48, n.12, p.925-934, 1992. BRANDI, S.D. Revestimentoduroporsoldagem. In: WAINER, E; BRANDI, S. D.; MELlO, F. D. H. (Org.) Soldagem: processos e metalurgia. São Paulo: Edgard Blücher, 2004. p.335-358.

LEITE, R. V. M.; MARQUES, P. V. Estudo comparativo da resistência ao desgaste abrasivo do revestimento de três ligas metálicas utilizadas na indústria, aplicadas por soldagem com arames tubulares. Soldagem \& Inspeção, v.14, n.4, p.329335,2009 .

LIMA, A. C.; FERRARESI, V. A. Análise da microestrutura e da resistência ao desgaste de revestimento duro utilizado pela indústria sucroalcooleira. Soldagem \& Inspeção, v.14, n.2, p.140-150, 2009.

MACHADO, A. L. T.; ESPÍRITO SANTO, A. C.; BATISTA, V. J.; REIS, A. V.; SPAGNOLO, R. T. Utilizaçáo de ferro fundido nodular austemperado em ponteiras sulcadoras de adubo de semeadoras de plantio direto. RevistaBrasileira de Agrociência, v.14, n.1, p.143-153, 2008.

NALBANT, M.; PALALI, A. T. Effects of different material coatings on the wearing of plowshares in soil tillage. TurkishJournalofAgriculture\&Forestry, v.35, p.215-223, 2011. MODENESI, P. J.; MARQUES, P. V.; SANTOS, D. B. Metalurgia da soldagem. Belo Horizonte: UFMG, 2010. 363p. MORAES, J. O. Avaliação da resistência ao desgaste abrasivo de risers flexíveis - Proposição de nova metodologia de teste. Dissertaçáo (Mestrado). Uberlândia:Universidade Federal de Uberlândia, 2005. 142p.

MOURAD, R. B. A.; SANTOS, J. E. G. DOS. Projeto e construçáo debancada para verificação do desgaste dos órgáos ativos de implementos agrícolas submetidos à abrasáo em quatro tipos de solos. Eng. Agríc., Jaboticabal, v.23 n.3, p.547555, 2003.

STRECK, E. V.; KÄMPF, N.; DALMOLIN, R. S. D.; KLAMT, E.; NASCIMENTO, P. C.; SCHNEIDER, P. Solos do Rio Grande do Sul. Porto Alegre: EMATER/RS - UFRGS, 2002. $107 \mathrm{p}$.

YAZICI, A. Investigation of the reduction of mouldboard ploughshare wear through hot stamping and hardfacing processes. Turkish Journal of Agriculture \& Forestry, v.35, p.461-468, 2011. 